\title{
Three Common Members of the Heath Family
} by Albert Karvonen, Edmonton

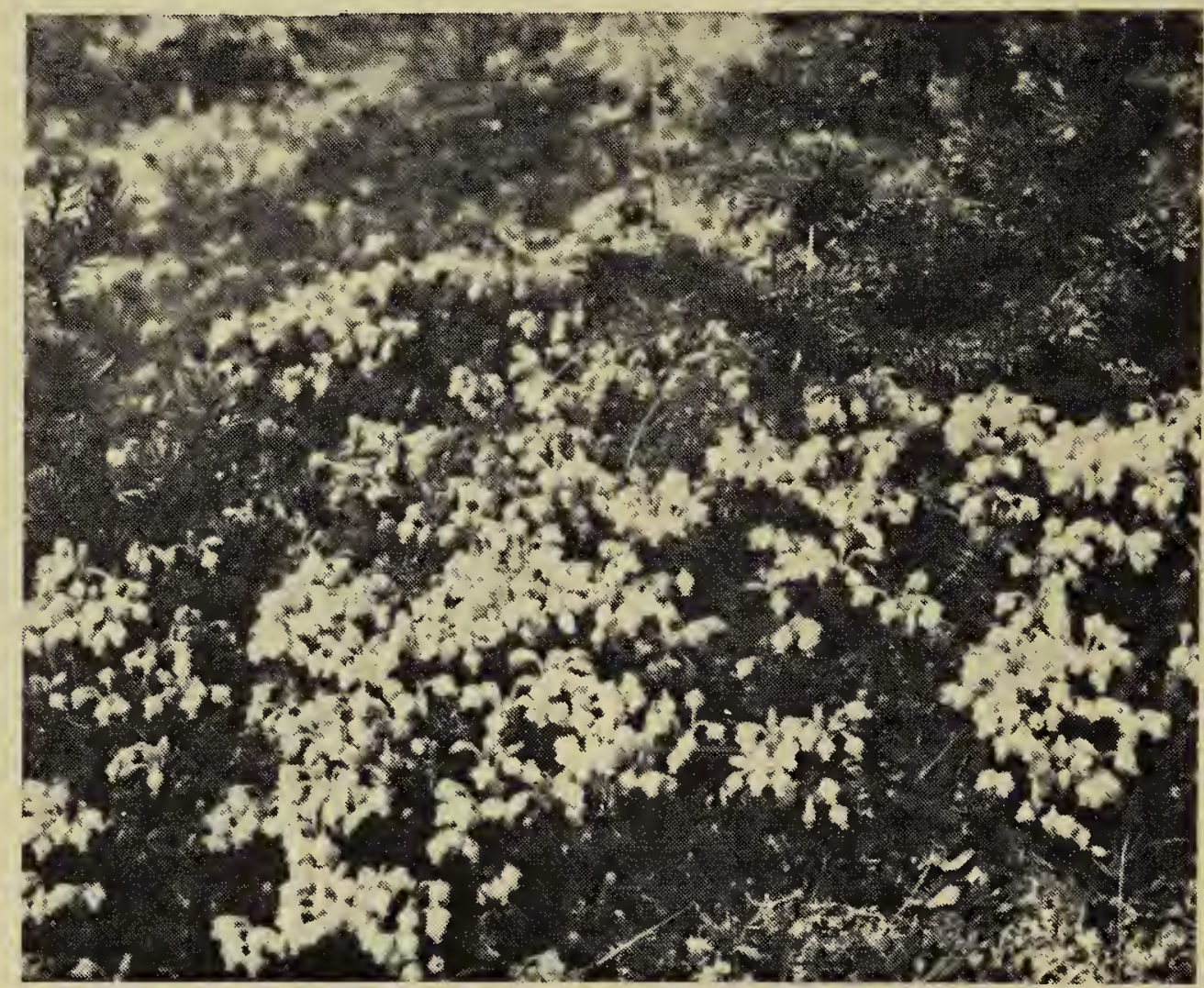

Yellow Heather at Magog Lake, 1963.

Fhoto by Albert Karvonen

No alpine trip in June or July would be complete without seeing one or more of our delicate mountain heaths. Three of the common
Canadian mountain heaths are shown here. These pictures are conversions from kodachrome II transparencies.

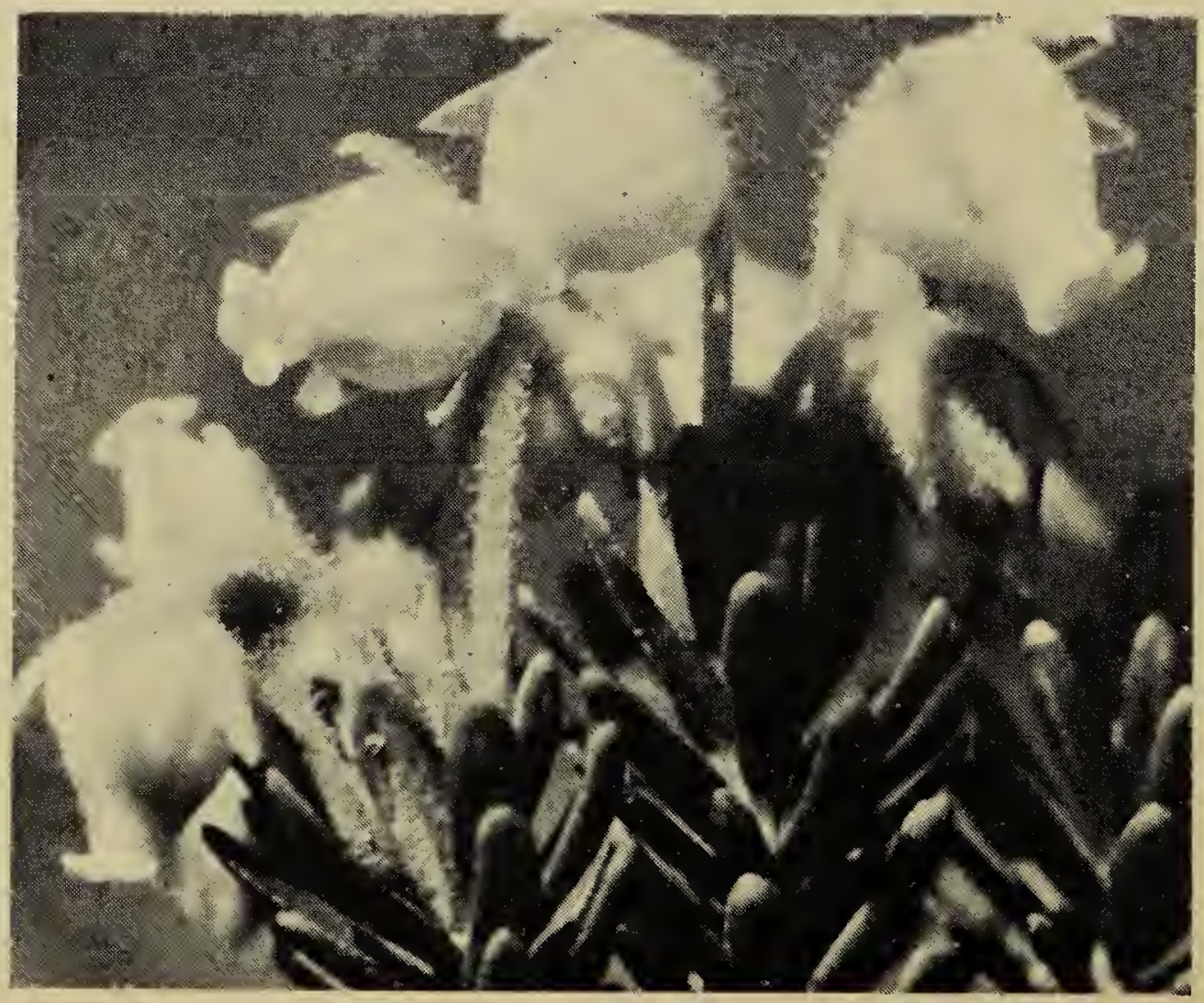

Photo by Albert Karvonen Flowers and leaves of Yellow Heather, Phyllodoce glanduliflora. 


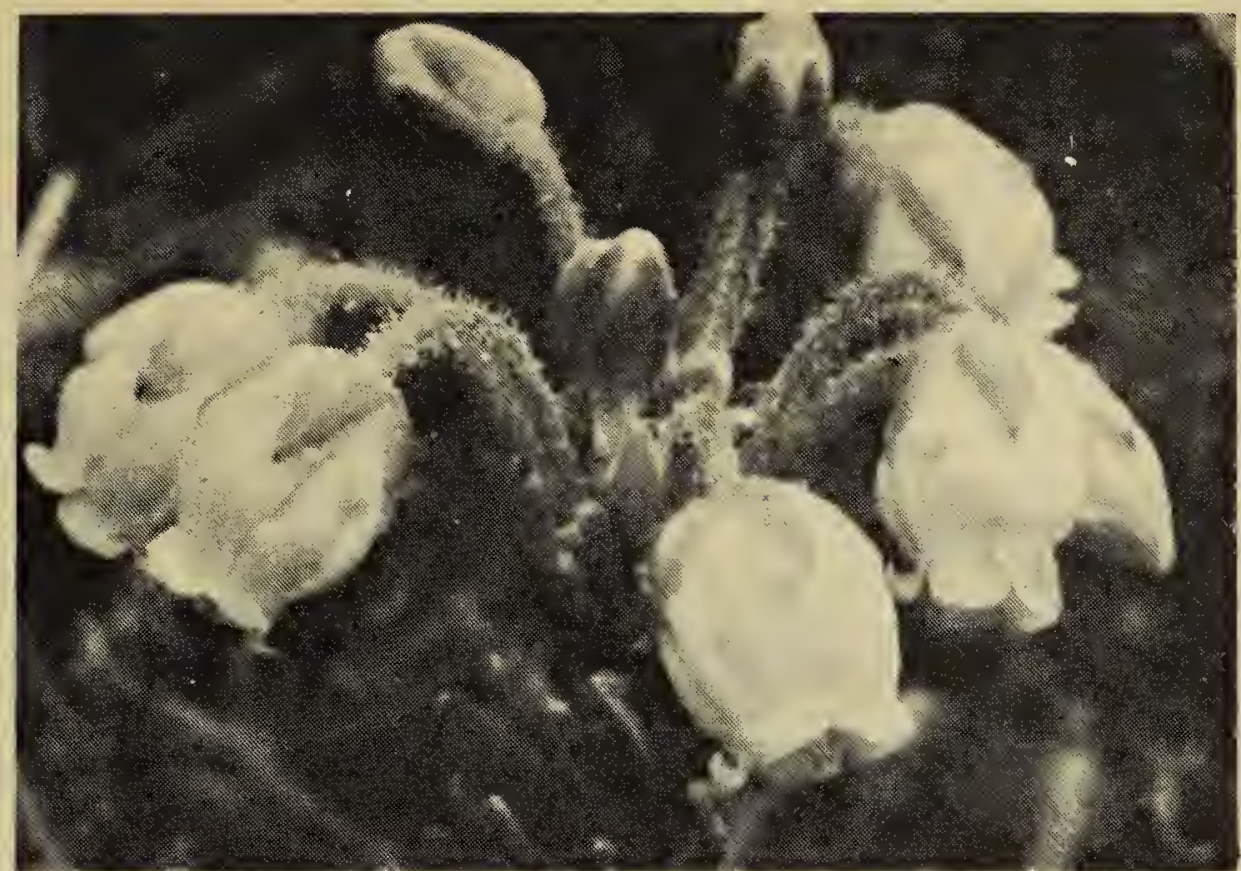

Fhoto by Albert Karvonen Flowers of Red Heather, Phyllodoce empetriformis.

The photos of Yellow Heather, Phyllodoce glanduliflora (Hook.) Cov., were taken at Magog Lake, Mount Assiniboine Provincial Park, British Columbia at 7,500 feet. Yellow Heather grows in unbroken masses of sulphur yellow and green forming a luxuriant carpet. The small pendant blooms are no more than about $1 / 8$ inch in diameter and the plant itself is only $3-10$ inches tall.

The photo of Red Mountain Heather, Phyllodoce empetriformis (Smith) D. Don., was taken at Lawson Lake, Kananaskis Lakes area, Alberta, at 7,000 feet. This fragrant alpine plant with rose-coloured flowers is only about 4-5 inches tall. It differs from the Yellow Heather in its flower colour and in the absence of hairs on the sepals. It shares its habitat of alpine meadows and open forests, usually close to lakes, with the Yellow Heather and the White Heather.

The photo of White Heather, Cassiope mertensiana (Bong.) D. Don., was taken near Magog Lake in British Columbia at 7,500 feet. The species name is from the mythical goddess of Mertens and the common name Mertens Mountain Heather is sometimes used. With its tiny belllike corollas, about $1 / 4$ inch in diameter, it is truly a miniature goddess of the alpine flowers. The graceful hanging bells are clasped by tiny finger-like sepals. The leaves are minute and scale-like and they give the slender stem a rope-like appear- ance. The plant prefers moist sunny slopes and grows to a height of about 6 inches.

The three heathers illustrated here play a prominent part in the lavish June and July floral mountain displays which are truly havens of beauty for the hiker and the ardent naturalist and photographer.

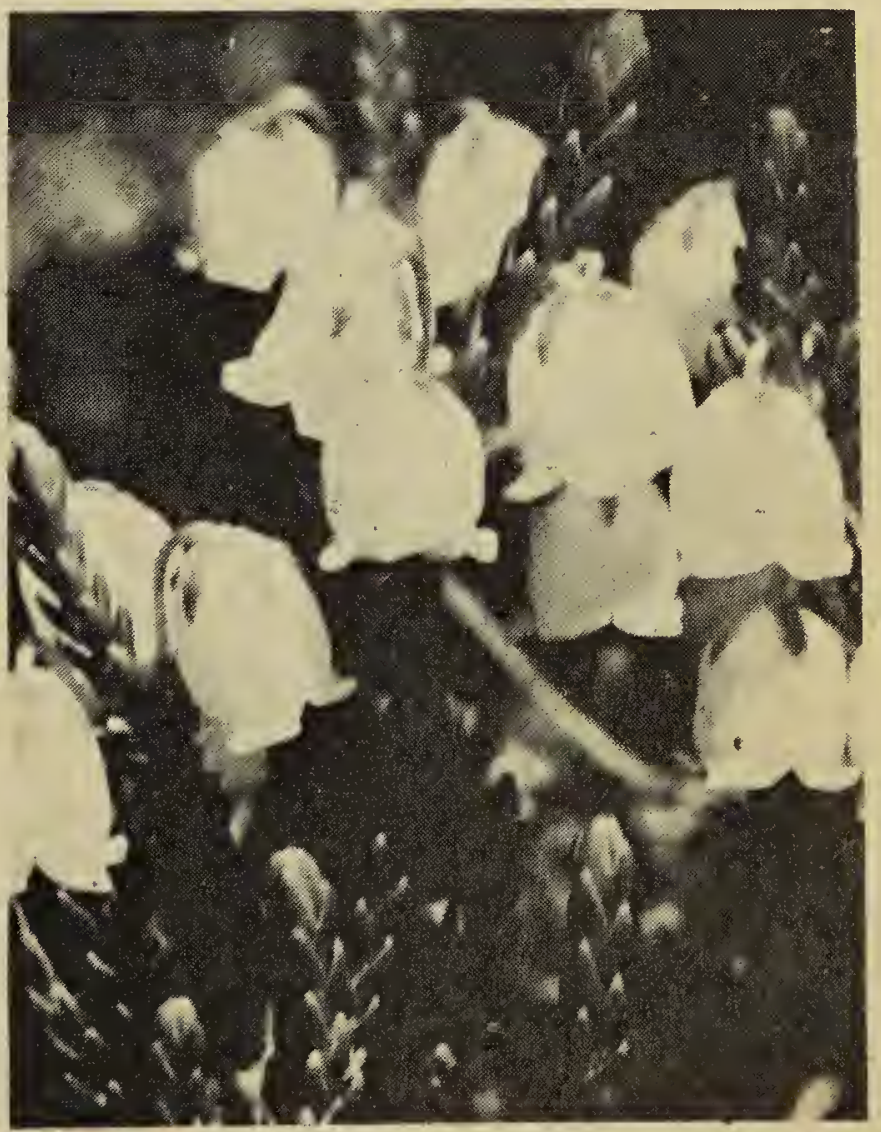

Photo by Albert Karvonen Flowers and leaves of White Heather, Cassiope mertensiana. 